\title{
Compact Ultra Wide-Band (UWB) CPW-fed Elliptical Monopole on Liquid Crystal Polymer (LCP)
}

\author{
Symeon Nikolaou ${ }^{(1)}$, Dimitrios E. Anagnostou ${ }^{*}(1)$, George E. Ponchak ${ }^{(2)}$, \\ Manos M. Tentzeris ${ }^{(1)}$ and John Papapolymerou ${ }^{(1)}$ \\ (1) School of ECE, Georgia Institute of Technology, Atlanta, GA 30332-0250, U.S.A. \\ (2) NASA Glenn Research Center, Cleveland, OH 44135, U.S.A. \\ simos@ece.gatech.edu
}

\begin{abstract}
The implementation of a compact CPW-fed elliptical monopole antenna that demonstrates good impedance match and omni-directional radiation patterns in the whole ultra wide band range (UWB) is discussed in this paper. The proposed antenna is fabricated on $100 \mu \mathrm{m}$ thick liquid crystal polymer (LCP) with an overall board dimension of $32 \mathrm{~mm}$ x $30 \mathrm{~mm}$. Return loss and radiation pattern measurements are in very good agreement with the simulated results.
\end{abstract}

\section{Introduction}

The Ultra Wide Band (UWB) [1] protocol using the spectrum from $3.1 \mathrm{GHz}$ to $10.6 \mathrm{GHz}$ is a new promising technology suitable for high rate communications in small distances. As a result, the design of compact UWB antennas has attracted a lot of attention in the recent years. The fat monopole solution was proposed by some researchers [2-3]. In this paper, a compact Coplanar Waveguide (CPW)-fed elliptical monopole is proposed on a Liquid Crystal Polymer (LCP) substrate. The elliptical shape and the CPW ground size provide control on the return loss. The proposed antenna has compact size, omni-directional patterns, and is a good candidate for many UWB applications.

\section{Antenna Design and Fabrication}

The proposed antenna was fabricated on a $100 \mu \mathrm{m}$ thick LCP substrate. The copper layer is only $3 \mu \mathrm{m}$ thick and it was sputtered onto the LCP substrate. The compact CPW-fed elliptical monopole schematic is presented in fig. 1. The overall size is very small. The length of the board is $S 1=32 \mathrm{~mm}$ and the width is $\mathrm{S} 2=30 \mathrm{~mm}$. It is fed by a CPW line where the central conductor width (W) is 2.94 $\mathrm{mm}$ and the slot gaps are $\mathrm{s}=100 \mu \mathrm{m}$ wide. The CPW line is linearly tapered to improve the matching of the elliptical radiator to the feeding line. At a distance $\mathrm{L} 2=6.10 \mathrm{~mm}$, the central conductor is linearly tapered down to $\mathrm{w}=0.85 \mathrm{~mm}$ at the point where the line connects to the elliptical radiator. Both ground planes are also tapered linearly in such a way so that the lower side is $\mathrm{H} 2=11.50 \mathrm{~mm}$ while the opposite side is $\mathrm{H} 1=12.07 \mathrm{~mm}$. The ground length is only $\mathrm{D}=9.60 \mathrm{~mm}$. Finally the elliptical radiator has major axis $A=9 \mathrm{~mm}$ and secondary axis $\mathrm{B}=6.75 \mathrm{~mm}$ with a ratio $\mathrm{B} / \mathrm{A}=0.75$. LCP was preferred because of its low dielectric constant $\left(\varepsilon_{\mathrm{r}}=3\right)$, low loss $(\tan \delta=0.002)$, and the fact that it is suitable for conformal antennas and easy to fabricate with an engineered CTE [4]. Standard photolithography was used for the fabrication. The design dimensions have been optimized in order for 
the antenna to be matched over a frequency range of $3 \mathrm{GHz}$ to $10 \mathrm{GHz}$. The antenna schematic dimensions are summarized in Table 1.

\section{Discussion of Measurements and Simulated Results}

For return loss and radiation pattern measurements, an SMA connector was soldered onto the CPW line. An HP 8530A network analyzer was used to measure the return loss. The simulated and measured results are presented in fig. 2, demonstrating a very good agreement. The return loss remains below $-10 \mathrm{~dB}$ over most of the UWB range, and is above $-10 \mathrm{~dB}$ only over a small frequency band above $10 \mathrm{GHz}$. Return loss is dominated by two major resonances, one at $4 \mathrm{GHz}$ and a second one close to $9 \mathrm{GHz}$. The lower resonance is controlled by the ground segment width, H2. Practically, as $\mathrm{H} 2$ is increased, the lower frequency resonance is shifted downward. The $9 \mathrm{GHz}$ resonance is primarily affected by the secondary axis length B; as B is reduced, the resonance shifts upward in frequency. If the two resonances are too close to each other, the return loss bandwidth cannot cover the whole UWB range and both lower and higher frequencies remain unmatched. If the two resonances are too far from each other, $\mathrm{S} 11$ is not below $-10 \mathrm{~dB}$ over a range of frequencies in the middle of the UWB frequency range. Therefore the dimensions were optimized to cover most of the UWB frequency range. Ansoft HFFS [5] was used to simulate and optimize the antenna parameters.

Radiation pattern measurements were taken in three different planes, the plane where the antenna lays and $\mathrm{E}$ and $\mathrm{H}$ planes. In all three cases, simulated and measured co-polarization is presented. Only measurements at $5 \mathrm{GHz}$ and $9 \mathrm{GHz}$ are presented, however the radiation patterns are similar over the whole UWB range. Based on the antenna orientation presented in fig. 1, figs $3 \mathrm{a}$ and $3 \mathrm{~b}$ present a $\varphi$ sweep on the $x-y$ plane for $f=5 \mathrm{GHz}$ and $\mathrm{f}=9 \mathrm{GHz}$ respectively. $\mathrm{x}$-axis corresponds to $\varphi=0^{\circ}$ while $y$-axis corresponds to $\varphi=90^{\circ}$. E plane cuts $(x-z)$ for the two frequencies are presented in figs $4 \mathrm{a}$ and $4 \mathrm{~b}$ where $\theta=0^{\circ}$ coincides with $\mathrm{z}$-axis and $\theta=90^{\circ}$ coincides with $\mathrm{x}$-axis. In the E-plane, the $\mathrm{x}$-axis is parallel to the feed line and results in a null in that direction. $\mathrm{H}$ plane $(\mathrm{y}-\mathrm{z})$ measurements are presented in figs. $5 \mathrm{a}$ and $5 \mathrm{~b}$, where it is seen that the pattern is omni-directional. $\mathrm{Z}$-axis corresponds again to $\theta=0^{\circ}$ while, in this case, $\theta=90^{\circ}$ coincides with y axis. In all cases simulations and measurements are in very good agreement. Small variations in the pattern and the pattern symmetry in the measured data are due to reflections and blockage caused by the SMA launcher, detector, and cable.

\section{Conclusion}

A compact, CPW-fed, elliptical monopole on an organic material (LCP) suitable for integration with other passive and active components is introduced and proposed for the UWB range. The presented antenna has omni-directional radiation patterns and this characteristic remains consistent with frequency. Return loss measurements verify that the proposed antenna is well matched in the whole UWB range while the antenna size is kept very small. Both return loss and 
radiation pattern measurements are in very good agreement with the simulated results. The antenna on LCP is conformal can be easily fabricated with relatively low cost and is a good candidate for a number of personal mobile communication devices.

\section{References:}

[1] Anon., FCC First Report and Order on Ultra-Wideband Technology, February 2002

[2] J. Liang, C. C. Chiau, X. Chen, and C. G. Parini, "Printed circular disc monopole antenna for ultra wideband applications", Electronic Letters, vol. 40, no. 7, pp. 1246-1248, September 2004

[3] T. Yang and W.A Davis, "Planar half-disc antenna structures for ultra wide-band communications," IEEE Ant. and Prop. Society Int. Symp. Dig., 2004, vol. 3, pp. 2508-2511, June 2004

[4] D.C. Thompson, O.Tantot, H. Jallageas, G.E. Ponchak, M.M. Tentzeris, J. Papapolymerou, "Characterization of liquid crystal polymer (LCP) material and transmission lines on LCP substrates from 30 to $110 \mathrm{GHz}$ ", IEEE Transactions on Microwave Theory and Techniques, vol. 52, no.4, pp. 1343-1352, April 2004

[5] Ansoft High Frequency Structure Simulator (HFSS). Ver. 9.1 Ansoft Corporation

Table 1. Antenna Dimensions

\begin{tabular}{cccc}
\hline S1 & $32.00 \mathrm{~mm}$ & B & $6.75 \mathrm{~mm}$ \\
S2 & $30.00 \mathrm{~mm}$ & $\mathrm{~W}$ & $0.85 \mathrm{~mm}$ \\
D & $9.60 \mathrm{~mm}$ & W & $2.94 \mathrm{~mm}$ \\
L1 & $7.23 \mathrm{~mm}$ & $\mathrm{~s}$ & $0.10 \mathrm{~mm}$ \\
L2 & $6.10 \mathrm{~mm}$ & $\mathrm{H} 1$ & $12.07 \mathrm{~mm}$ \\
A & $9.00 \mathrm{~mm}$ & H2 & $11.50 \mathrm{~mm}$ \\
\hline \hline
\end{tabular}

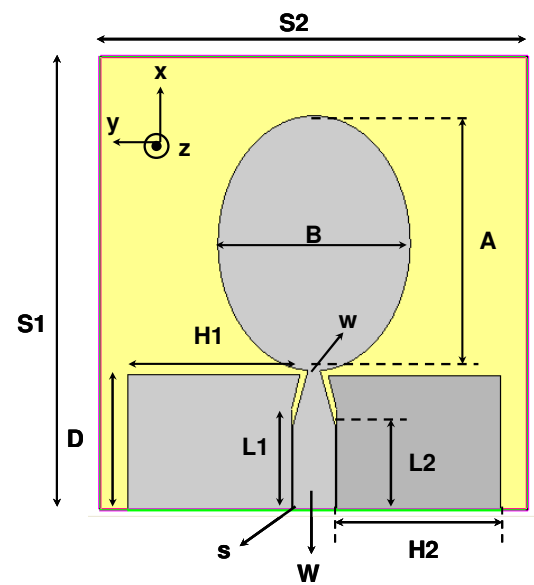

Fig. 1: Antenna Schematic

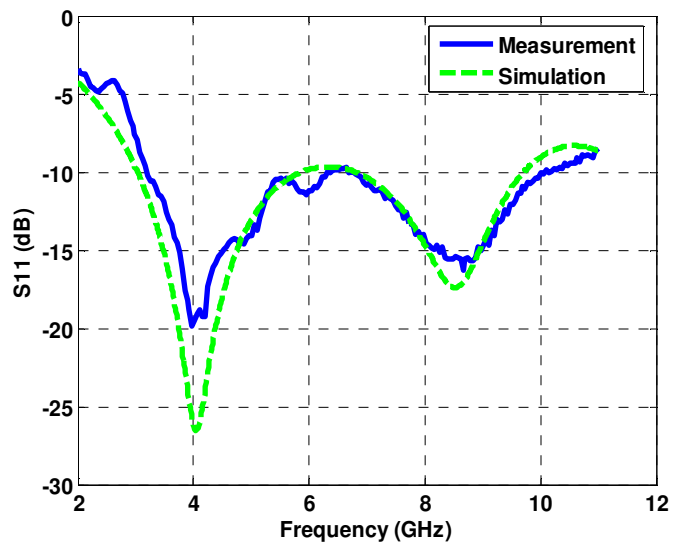

Fig. 2: Return Loss S11 


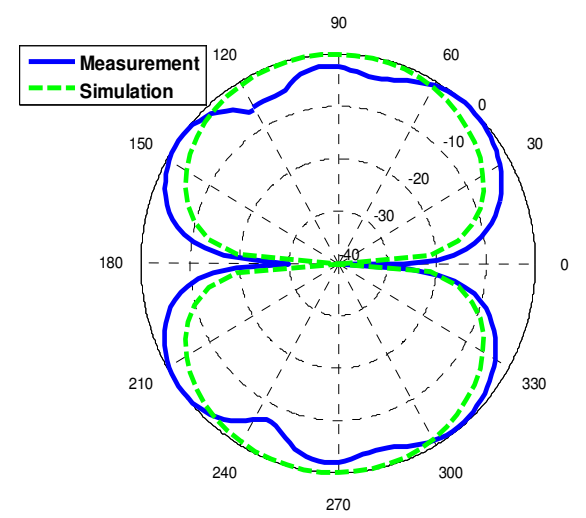

Fig. 3a : f=5 GHz Phi Sweep (x-y)

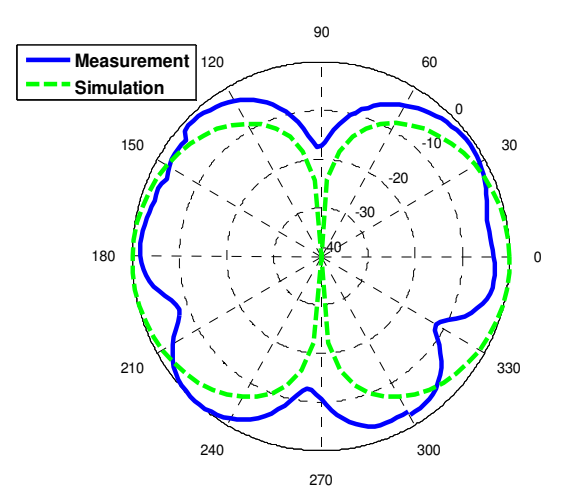

Fig. 4a: f=5 GHz E Plane (x-z)

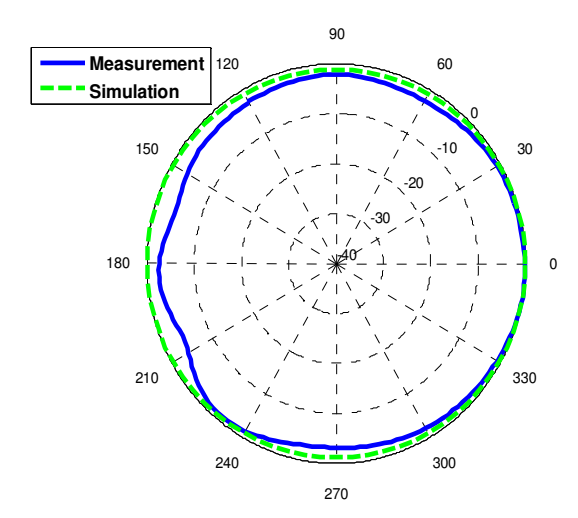

Fig. 5a: $f=5$ GHz H Plane (y-z)

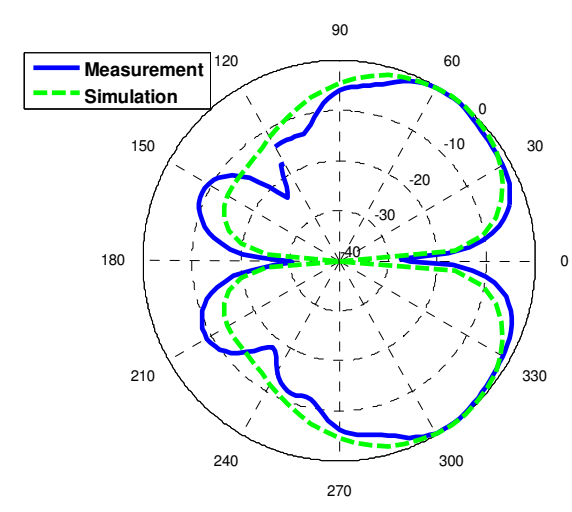

Fig. 3b: $f=9$ GHz Phi Sweep (x-y)

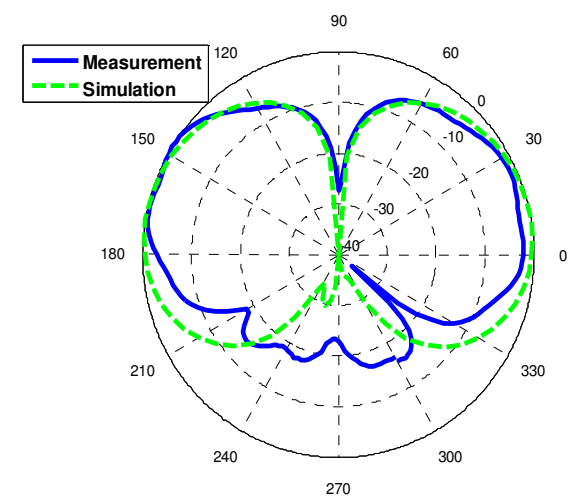

Fig. 4b: $\mathrm{f}=9 \mathrm{GHz}$ E Plane (x-z)

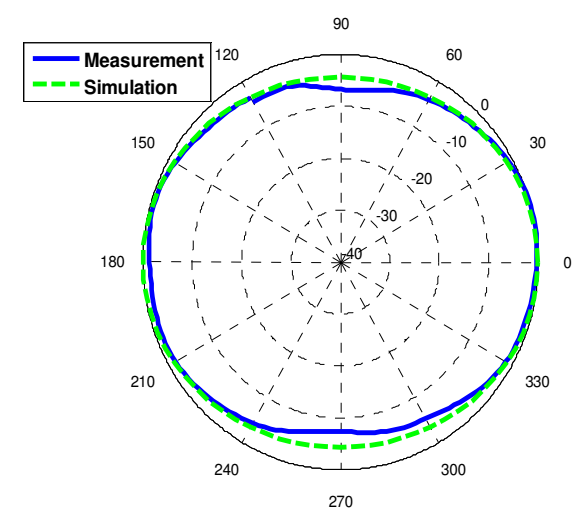

Fig. 5b: $f=9 \mathrm{GHz} H$ Plane $(\mathrm{y}-\mathrm{z})$ 